\title{
Crustal velocity structure of the Deccan Volcanic Province, Indian Peninsula, from observed surface wave dispersion
}

\author{
Gaddale Suresh $^{1,{ }^{\star}}$, Satbir S. Teotia ${ }^{2}$, Sankar N. Bhattacharya ${ }^{1}$ \\ ${ }^{1}$ India Meteorological Department, Seismology Division, New Delhi, India \\ ${ }^{2}$ Kurukshetra University, Department of Geophysics, Kurukshetra, India
}

\section{Article history}

Received April 10, 2014; accepted June 10, 2014.

Subject classification:

Deccan Volcanic Province, Surface waves, Crustal structure.

\begin{abstract}
Through inversion of fundamental mode group velocities of Love and Rayleigh waves, we study the crustal and subcrustal structure across the central Deccan Volcanic Province (DVP), which is one of the world's largest terrestrial flood basalts. Our analysis is based on broadband seismograms recorded at seismological station Bhopal (BHPL) in the central India from earthquakes located near west coast of India, with an average epicentral distance about $768 \mathrm{~km}$. The recording station and epicentral zone are situated respectively on the northern and southern edges of DVP with wave paths across central DVP. The period of group velocity data ranges from 5 to $60 \mathrm{~s}$ for Rayleigh waves and 5 to $45 \mathrm{~s}$ for Love waves. Using the genetic algorithm, the observed data have been inverted to obtain the crust and subcrustal velocity structure along the wavepaths. Using this procedure, a similar velocity structure was also obtained earlier for the northwestern DVP, which is in the west of the present study region. Comparison of results show that the crustal thickness decreases westward from central DVP $(39.6 \mathrm{~km})$ to northwestern DVP $(37.8 \mathrm{~km})$ along with the decrease of thickness of upper crust; while the thickness of lower crust remains nearly same. From east to west $S$-wave velocity in the upper crust decreases by 2 to 3 per cent, while P-wave velocity in the whole crust and subcrust decreases by 3 to 6 per cent. The P-and S-wave velocities are positively correlated with crustal thickness and negatively correlated with earth's heat flow. It appears that the elevated crustal and subcrustal temperature in the western side is the main factor for low velocities on this side.
\end{abstract}

\section{Introduction}

The Deccan Volcanic Province (DVP) is the most remarkable continental flood basalts provinces of the Indian Peninsula and formed around $65 \mathrm{My}$, when this region passed over the Reunion hotspot during its northward movement [Duncan and Pyle 1988]. The DVP has emerged as most interesting subjects of research particularly for its enormous size. The west coast and Narmada-Son lineament are the probable source regions from which the Deccan lavas were poured out through tensional fractures [Sen 2001]. The lava flowed great distances towards east and south to form the largest terrestrial flood cover extending nearly half a million square $\mathrm{km}$ between latitudes $16-24^{\circ} \mathrm{N}$ and longitudes $70-77^{\circ} \mathrm{E}$ (Figure 1). The flood basalts are known as Deccan traps.

There are several studies in the past to evaluate the lithospheric velocity structure of the Indian Peninsula using body waves and surface waves from regional and teleseismic earthquakes. Dube et al. [1973] used body wave records of observatories situated in the Peninsular India from 40 earthquakes occurred in the Koyna region (Figure 1). Bhattacharya [1981] inverted the surface wave group velocities along paths in the central India and obtained the model IP11. Bhattacharya [1991] found that IP11 also satisfies the surface wave group velocity data across the northwestern part of the Indian Peninsula. Furthermore, reviewing the surface wave studies in the Indian Peninsula, Bhattacharya [1992] noted that the short period (0.6 to 2.5 s) surface wave data across the Koyna region (in southern DVP) are satisfied by IP12 (Figure 2); IP12 is same as IP11 except the top $1 \mathrm{~km}$ of latter is replaced by a Deccan trap layer. Singh et al. [1999] obtained velocity structure using surface waves recorded at regional distances from 1997 Jabalpur earthquake in the central India (Figure 2). From the same earthquake, Rao et al. [2002] used body waves at regional distances and refined the velocity model in a grid search method through ray tracing. Figure 2 summarizes the $S$-wave velocity structure of central India from these studies and shows that main difference is in the depth of the interface between layers of upper and lower crust. The crustal $S$-wave velocity model of Rao et al. [2002] agrees with that of Singh et al. [1999]; however, there are differences in Moho depth and $P$-wave velocities 


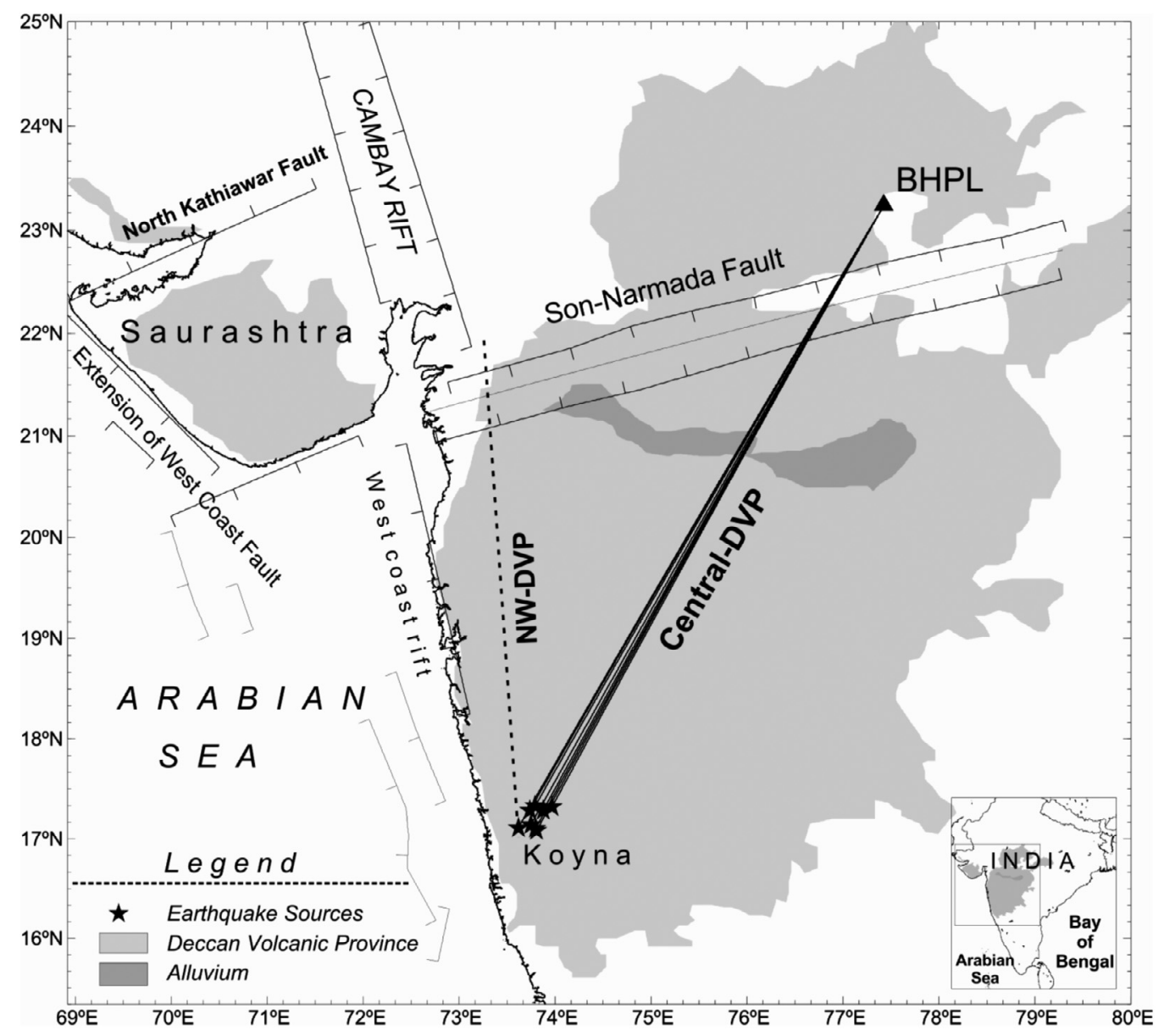

Figure 1. Major tectonic features of the Deccan Volcanic Province (DVP). Shaded area indicates the DVP. Wavepaths from the epicentres of Koyna earthquakes to Bhopal (BHPL) have been shown in solid lines (present study) and are through central DVP. The dotted line is the mean wave path considered for evaluating the structure of northwest DVP [Prajapati et al. 2011].

between these two models. The Moho depth of Singh et al. [1999] is nearly same as that of IP11 or IP12 [Bhattacharya 1992].

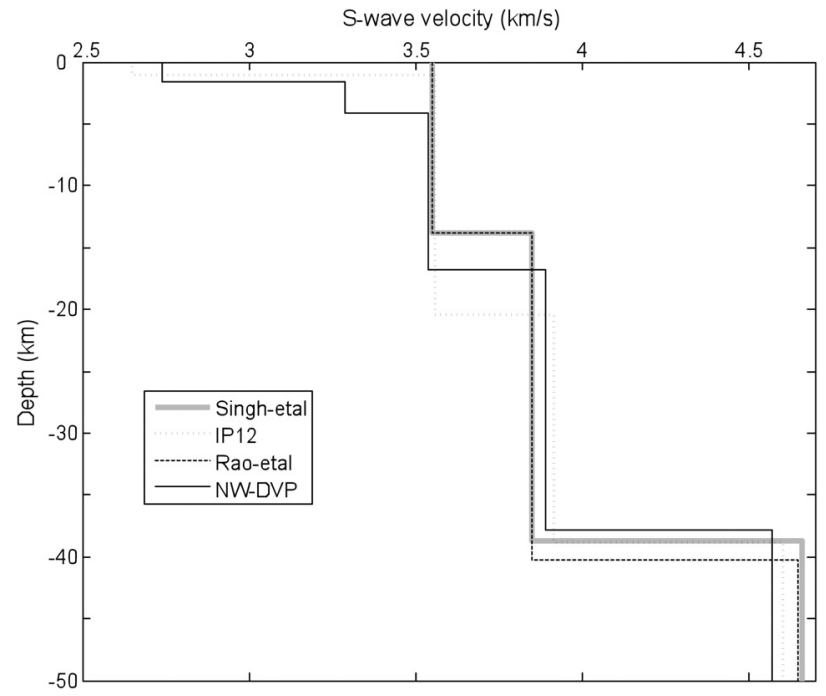

Figure 2. $S$-wave velocity structure of the Indian Peninsula in various studies: Singh-etal [Singh et al. 1999], IP12 [Bhattacharya 1992], Rao-etal [Rao et al. 2002], northwestern DVP [Prajapati et al. 2011]. Theoretical group velocity curves have been drawn in Figure 3 for these structures. IP12 is modified from IP11 [Bhattacharya 1981, 1992], whose top $1 \mathrm{~km}$ is replaced by a Deccan trap layer.
The crustal structure of northwestern DVP was obtained by Prajapati et al. [2011] using observed surface wave dispersion of Rayleigh and Love waves along a few wavepaths across this region. The mean wavepath of this study is shown in Figure 1; we shall refer this region crossed by the wavepaths in northwestern DVP and studied by Prajapati et al. [2011] as northwestern DVP. The authors also evaluated the crustal structure of the adjoining continental shelf. In the present study, we shall evaluate the velocity structure of crust and subcrust (a layer below the crust) of central DVP which is east of northwestern DVP (Figure 1). We shall note the changes in the structure of DVP as we shift westward from central to coastal DVP region. Study of these changes will improve our understanding of the geology, tectonics and geodynamics processes of DVP.

\section{Data and measurement of group velocity}

To select surface wavepaths across central-DVP, we consider the broadband records of the station Bhopal (BHPL), which is located in the northern part of DVP and analyze earthquakes occurred in the Koyna region in the west coast of India (Figure 1). The station BHPL is located on hard exposed bed-rock and has low ambi- 


\begin{tabular}{|c|c|c|c|c|c|c|c|}
\hline $\begin{array}{c}\text { Event } \\
\text { no. }\end{array}$ & $\begin{array}{c}\text { Date } \\
(\text { yyyy/mm/dd })\end{array}$ & $\begin{array}{l}\text { Origin time } \\
\text { hh:mm:ss }\end{array}$ & $\begin{array}{l}\text { Longitude } \\
\left({ }^{\circ} \mathrm{E}\right)\end{array}$ & $\begin{array}{l}\text { Latitude } \\
\left({ }^{\circ} \mathbf{N}\right)\end{array}$ & $\begin{array}{l}\text { Depth } \\
(\mathbf{k m})\end{array}$ & Magnitude & $\begin{array}{l}\text { Used } \\
\text { for }^{\star}\end{array}$ \\
\hline 1 & $1998 / 02 / 11$ & 01:08:49.1 & 73.965 & 17.321 & 33.0 & $4.2(\mathrm{mb})$ & LQ, LR \\
\hline 2 & $2000 / 09 / 05$ & $00: 32: 43.1$ & 73.790 & 17.332 & 10.0 & $5.4(\mathrm{mb})$ & LQ, LR \\
\hline 3 & $2005 / 03 / 14$ & 09:43:49.8 & 73.873 & 17.288 & 26.8 & $4.7(\mathrm{mb})$ & LQ, LR \\
\hline 4 & $2006 / 04 / 17$ & $16: 39: 59.4$ & 73.805 & 17.083 & 11.8 & $4.4(\mathrm{mb})$ & LQ, LR \\
\hline 5 & $2007 / 11 / 24$ & $10: 57: 47.0$ & 73.744 & 17.141 & 9.0 & $4.8(\mathrm{Mw})$ & LQ, LR \\
\hline 6 & $2008 / 09 / 16$ & $21: 47: 13.3$ & 73.734 & 17.287 & 15.0 & $5.0(\mathrm{Mw})$ & LQ, LR \\
\hline 7 & $2009 / 11 / 14$ & $13: 03: 32.8$ & 73.792 & 17.102 & 14.8 & $4.7(\mathrm{Mw})$ & LQ, LR \\
\hline 8 & $2009 / 12 / 12$ & $11: 51: 24.8$ & 73.613 & 17.112 & 9.7 & $5.1(\mathrm{Mw})$ & LQ, LR \\
\hline
\end{tabular}

Table 1. List of earthquakes used for evaluating group velocities. ${ }^{\star} \mathrm{LQ}=$ Love wave, $\mathrm{LR}=$ Rayleigh wave.

ent ground noise. We consider well recorded surface waves from earthquakes of magnitudes between 4.2 and 5.4 (Table 1). A three component velocity broadband seismogram of BHPL for the April 17, 2006, Koyna earthquake ( $m b 4.4)$ is shown in Figure 3 indicating well recorded surface waves which are prominent compared to the body waves. The hypocentral parameters of the earthquakes are determined using SEISAN analysis software [Havskov and Ottemoeller 1999] utilizing the phase data of regional seismological observatories. All the events were located using IP12 velocity model [Bhattacharya 1992]. Table 1 lists the hypocentral parameters of earthquakes considered; the wavepaths from all these events to the recording station at Bhopal are through the central portion of DVP (Figure 1). Bhopal $\left(23.241^{\circ} \mathrm{N}, 77.424^{\circ} \mathrm{E}, 520 \mathrm{~m}\right)$ is a part of National Seismological Network of India Meteorological Department (IMD), equipped with three component broadband sensor, Nanometrics Trillium-240 (with flat $3 \mathrm{~dB}$ velocity response from $240 \mathrm{~s}$ to $35 \mathrm{~Hz}$ ) and accelerometer TSA-400S (with flat $3 \mathrm{~dB}$ acceleration response from DC to $225 \mathrm{~Hz}$ ) connected to the six channel 24 bit digitizer (Taurus with Trident) and internal time offsets are adjusted by GPS receiver automatically. The station is connected to Central Receiving Station in Delhi and Tsunami Warning Center at INCOIS, Hyderabad through VSAT communication facilities for near real time transfer of continuous recorded data and to perform scheduled quality checks [Dattatrayam et al. 2009]. The station is also equipped with broadband seismometer STS-2 connected to Quanterra digitizer (Q680LVG) [Bhattacharya and Dattatrayam 2000]. The average epicentral distance from Koyna earthquakes to BHPL is about $768 \mathrm{~km}$.

The group velocities are obtained through frequency-time-analysis (FTAN) as described in Dziewonskei et al. [1969] and Bhattacharya [1981, 1983]. For each event the 3-component 100 SPS (samples per second) data of BHPL is (1) decimated to 5 SPS, (2) changed to ground motion using the seismograph response and (3) converted to vertical, radial and transverse components. The vertical component is used for Rayleigh wave and transverse component for Love wave. In FTAN, the seismogram is passed through narrow Gaussian filter centered at each period. The time of the peak of the envelope to the amplitudes of the filtered seismogram gives the group arrival time $\left(t_{g}\right)$ and the group velocity $=\Delta / t_{g}$, where $\Delta$ is the epicentral distance. Such filtering makes it easier to separate different modes. The error in hypocenter determination is minimized by locating the earthquakes using regional structure and using phase data from regional observatories [Bhattacharya and Dattatrayam 2000]. Consequently, the error in epicenter is less than $5 \mathrm{~km}$ and the error in origin time is within $1 \mathrm{~s}$; considering average epicentral distance of $768 \mathrm{~km}$, these two errors cause an error less than 0.03 $\mathrm{km} / \mathrm{s}$ in group velocity measurement from a single event. However, these errors are reduced by considering the mean of the group velocities from many events;

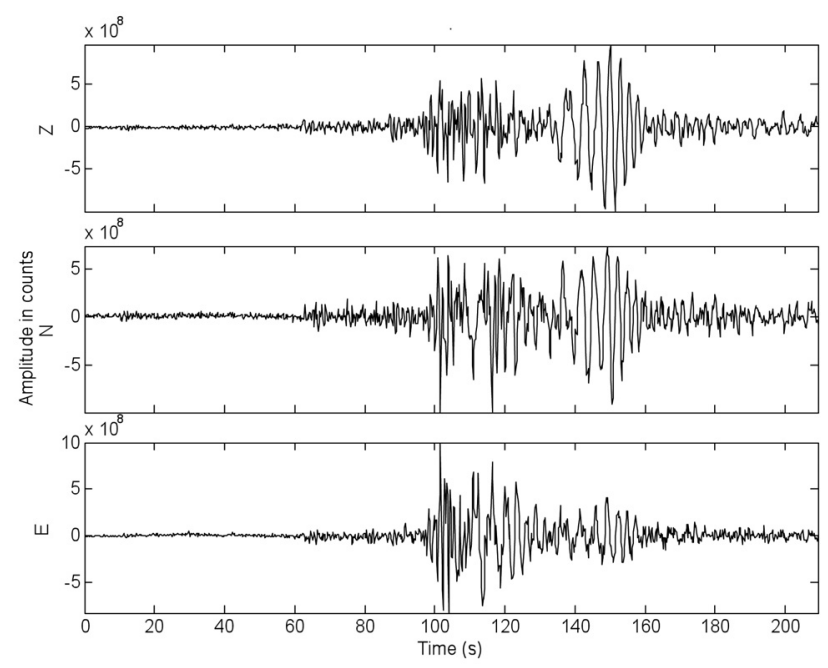

Figure 3. Broadband waveform of BHPL from the April 17, 2006, Koyna earthquake $\left(\Delta=7.01^{\circ}, m b=4.4\right.$, Table 1 , event no. 4). Waveform starts at 16:44:55.78. Although the amplitudes of body waves are weak but Rayleigh and Love waves are strong. 


\begin{tabular}{|c|c|c|c|c|c|c|}
\hline \multirow{2}{*}{$\begin{array}{l}\text { Period } \\
\text { (s) }\end{array}$} & \multicolumn{3}{|c|}{ Rayleigh waves } & \multicolumn{3}{|c|}{ Love waves } \\
\hline & $\begin{array}{l}\text { Group velocity } \\
(\mathrm{km} / \mathrm{s})\end{array}$ & $\begin{array}{c}\text { S.D. } \\
(\mathrm{km} / \mathrm{s})\end{array}$ & $\begin{array}{c}\text { Number of } \\
\text { measurements }\end{array}$ & $\begin{array}{l}\text { Group velocity } \\
\qquad(\mathbf{k m} / \mathbf{s})\end{array}$ & $\begin{array}{c}\text { S.D. } \\
(\mathrm{km} / \mathrm{s})\end{array}$ & $\begin{array}{c}\text { Number of } \\
\text { measurements }\end{array}$ \\
\hline 5.000 & 3.064 & 0.034 & 8 & 3.356 & 0.024 & 8 \\
\hline 5.741 & 3.074 & 0.051 & 8 & 3.365 & 0.017 & 8 \\
\hline 6.591 & 3.105 & 0.042 & 8 & 3.407 & 0.026 & 8 \\
\hline 7.568 & 3.156 & 0.037 & 8 & 3.428 & 0.022 & 8 \\
\hline 8.689 & 3.123 & 0.035 & 8 & 3.461 & 0.025 & 8 \\
\hline 9.976 & 3.143 & 0.035 & 8 & 3.469 & 0.024 & 8 \\
\hline 11.454 & 3.127 & 0.069 & 8 & 3.458 & 0.021 & 8 \\
\hline 13.151 & 3.102 & 0.046 & 8 & 3.468 & 0.033 & 8 \\
\hline 15.100 & 3.079 & 0.051 & 8 & 3.458 & 0.041 & 8 \\
\hline 17.337 & 3.102 & 0.051 & 8 & 3.484 & 0.019 & 8 \\
\hline 19.905 & 3.143 & 0.105 & 8 & 3.529 & 0.042 & 8 \\
\hline 22.854 & 3.168 & 0.143 & 8 & 3.569 & 0.077 & 8 \\
\hline 26.240 & 3.363 & 0.078 & 8 & 3.629 & 0.050 & 8 \\
\hline 30.128 & 3.484 & 0.106 & 8 & 3.673 & 0.051 & 8 \\
\hline 34.592 & 3.636 & 0.068 & 7 & 3.769 & 0.102 & 7 \\
\hline 39.716 & 3.797 & 0.136 & 4 & 3.998 & 0.113 & 5 \\
\hline 45.600 & 3.900 & 0.150 & 3 & 4.079 & 0.132 & 5 \\
\hline 52.356 & 3.989 & 0.173 & 3 & & & \\
\hline 60.113 & 4.097 & 0.092 & 3 & & & \\
\hline
\end{tabular}

Table 2. Observed group velocities across central DVP.

an estimate for the uncertainty may be seen from the standard deviations of the group velocities. The group velocities are for periods ranging from 5 to $60 \mathrm{~s}$ for fundamental mode Rayleigh wave and from 5 to $45 \mathrm{~s}$ for fundamental mode Love waves (Table 2, Figures 4 and 5). Because of this limited distance and moderate magnitude of usable earthquakes, no reliable surface wave dispersion measurements could be possible for longer periods. The standard deviations are generally higher for Rayleigh wave than for Love wave. Perhaps this can be explained by the source mechanisms of the earthquakes, which caused amplitudes of Love wave relatively stronger than those of Rayleigh wave at the azimuth of the station from the sources.

\section{Comparison of observed group velocity data}

In Figure 4 the observed mean group velocity data is compared with the theoretical dispersion curves for the previously evaluated models (Figure 2) in the Indian Peninsula discussed in the Introduction. The theoretical curves have been drawn following Bhattacharya [1987]. These theoretical curves are close to the observed data between 25 and $50 \mathrm{~s}$. For Love wave, the dispersion curve for IP12 agrees with the observed data even at lower periods while that for the model of Singh et al. [1999] is close to Rayleigh wave data in this period range. At lower periods (5-25 s), the observed group velocities across central DVP are significantly higher than those of the dispersion curves of northwestern DVP; this implies a relatively higher wave speed structure in the upper crust for central DVP. At periods above $25 \mathrm{~s}$, the Rayleigh and Love wave group velocities are only slightly more to that of northwestern DVP, which shows no significant change in lower crust and upper mantle shear velocity structure between them. However, this observation indicates that the crust and upper mantle velocities in central DVP are on average faster than those of northwestern DVP.

\section{Inversion and lithospheric structure}

The observed dispersion is a nonlinear function of the medium parameters viz., shear-, compressionalwave velocities, density and thickness of each layer. In order to obtain these model parameters through joint inversion of Rayleigh and Love wave group velocities, we apply a nonlinear inversion through Genetic Algorithms (GA) [Lomax and Snieder 1995, Yamanaka and Ishida 1996, Suresh et al. 2008]. The GA is configured to 

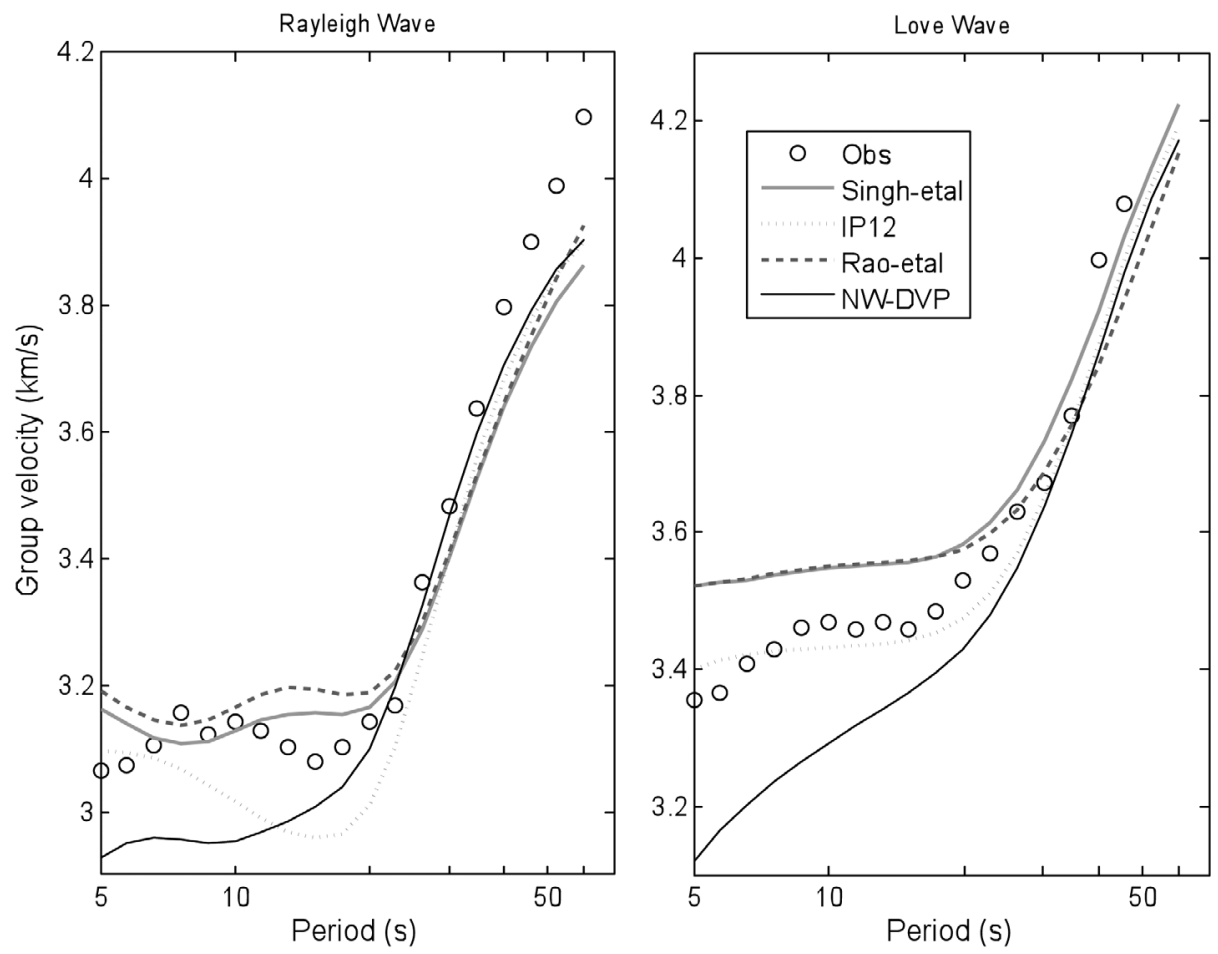

Figure 4. The theoretical group velocity curves for different structures (Figure 3) of the Indian Peninsula are compared with the present mean observed data across central DVP.
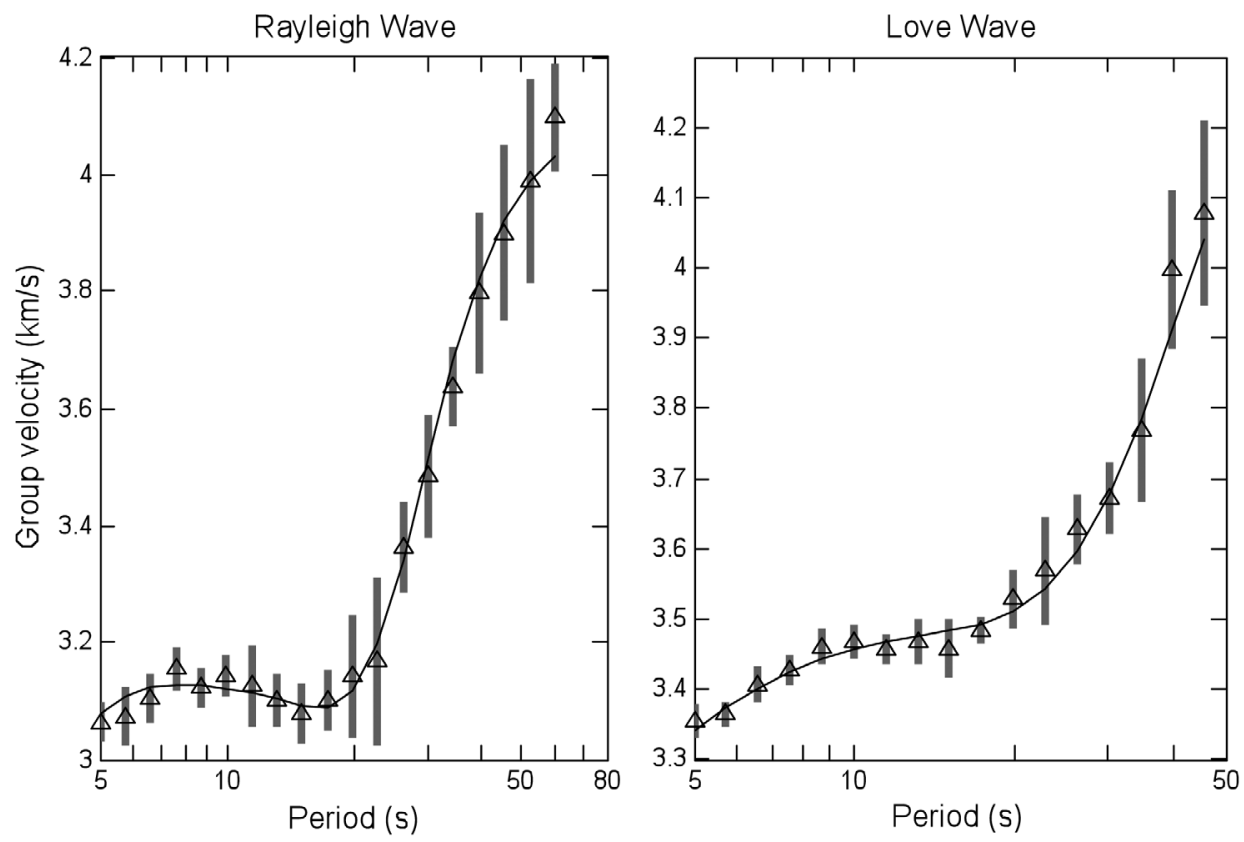

Figure 5. Observed mean group velocity data (open triangles) with \pm one standard deviation. The theoretical curve has been drawn for the structure of central DVP (Table 4).

find acceptable solutions within a user defined search space. During this process, the solution at each generation is improved with misfit between observed and theoretical group velocities becoming less or equal to the preceding generation. Here, the misfit $\varphi$ is considered similar to Prajapati et al. [2011] and is given by

$$
\varphi=\max \left[\frac{\delta_{i}^{R}}{\sigma_{i}^{R}}, \frac{\delta_{j}^{L}}{\sigma_{j}^{L}}\right]
$$

where, $\delta_{i}^{R}$ is the absolute difference between the observed and theoretical group velocity of a given structure, $\sigma_{i}^{R}$ is the standard deviation of the observed group velocity at period $T_{i}(i=1,2, \ldots, N R)$ for Rayleigh waves. $\delta_{j}^{L}$ and $\sigma_{j}^{L}$ are the corresponding values at pe$\operatorname{riod} \operatorname{Tj}(j=1,2, \ldots, \mathrm{NL})$ for Love waves. The misfit $\varphi$ gives a measure of closeness of the theoretical curve to the observed data with respect to standard deviation. A model is acceptable if $\varphi<1$ and in such a case theoret- 
ical curves of this model are within the limits of one standard deviation around each mean observation.

We keep the search space extended down to the depth $100 \mathrm{~km}$; this depth limit is due to limit of the longer periods of the observed data. While performing the inversion, we have evaluated the model parameters of the top 5 layers consisting of 4 layers of the crust and a layer of subcrust, whose base is fixed at $100 \mathrm{~km}$ depth as in Prajapati et al. [2011]. Below $100 \mathrm{~km}$ the structure is same as in IP11 [Bhattacharya 1981]. Such 4-layered crust has also been obtained by forward modeling of gravity data derived from surface measurements on the Indian Peninsula [Arora et al. 2012]. The 14 variables in our GA search are: (1-4) thickness of top 4 layers of the crust, (5-9) $V_{S}$ of the top 5 layers and (10-14) $V_{P} / V_{S}$ of top 5 layers. Here, $V_{P}$ is $P$-wave velocity and $V_{S}$ is $S$-wave velocity. The search space of these 14 variables is wide around the model parameters of those of northwestern DVP (Table 3). The density in each layer has been kept constant because it has the least effect on the dispersion curves and the density is considered in each layer as in northwestern DVP (Table 3).

The GA begins with a random initial population of $\mathrm{K}$ random models within solution limits. We consider a population of size $\mathrm{K}=60$ at each generation, where we create a new population with two elite members, 46 members through crossover and 12 members by mutation; the elite members replace the worst mod- els in the current generation with the best individuals of previous generation, so that the best individuals are not lost [Yamanaka and Ishida 1996]. Each GA operation gives best solution within 150 generations and the best solution is accepted. Such operation is repeated making a list of 40 accepted solutions and the misfit value of all these solutions are between 0.74 and 0.83 . The mean and standard deviations (SD) for each of varying parameters of all the 40 accepted solutions are obtained (Table 4). The SD generally shows the error in the results. $V_{P}$ is obtained from $V_{S}$ and $V_{P} / V_{S}$ for each solution; the mean and $\mathrm{SD}$ of $V_{P}$ are also obtained. This model with mean values is considered as the model for central DVP. The misfit for this model is 0.77 ; this misfit value shows that the theoretical curves are within the SD of the observed data.

\section{Discussion}

Central DVP mostly lies in the central India. Comparing present result with other studies for different areas in the central India [Bhattacharya 1981, Singh et al. 1999, Rao et al. 2002] (Figure 2), we find $V_{S}$ varies between 3.55 and $3.65 \mathrm{~km} / \mathrm{s}$ in the upper crust and between 3.85 and $3.92 \mathrm{~km} / \mathrm{s}$ in the lower crust; in the subcrust $V_{S}$ varies between 4.60 and $4.68 \mathrm{~km} / \mathrm{s}$. Thus in the central India, the variation of $V_{S}$ around mean value is 2 per cent in the upper crust and these variations are 1 per cent in lower crust and subcrust. There is large vari-

\begin{tabular}{lccccc}
\hline Layer & $\begin{array}{c}\text { Depth of } \\
\text { top layer } \\
(\mathbf{k m})\end{array}$ & $\begin{array}{c}\text { Thickness } \\
\text { of layer } \\
(\mathbf{k m})\end{array}$ & $\begin{array}{c}P \text {-wave } \\
\text { velocity } \\
(\mathbf{k m} / \mathbf{s})\end{array}$ & $\begin{array}{c}S \text {-wave } \\
\text { velocity } \\
(\mathbf{k m} / \mathbf{s})\end{array}$ & $\begin{array}{c}\text { Density } \\
\left(\mathbf{g m} / \mathbf{c m}^{3}\right)\end{array}$ \\
\hline 1. Deccan trap & 0.0 & 1.6 & 4.79 & 2.74 & 2.40 \\
2. Shallow crust & 1.6 & 2.5 & 5.78 & 3.29 & 3.54 \\
3. Upper crust & 4.1 & 12.7 & 6.12 & 3.89 & 2.50 \\
4. Lower crust & 16.8 & 21.0 & 6.58 & 4.57 & 3.01 \\
5. Subcrust & 37.8 & 62.2 & 8.09 & 3.30 \\
\hline
\end{tabular}

Table 3. The crust and subcrustal structure for northwestern DVP down to $100 \mathrm{~km}$ [Prajapati et al. 2011]. Below $100 \mathrm{~km}$ the structure is same as that of IP11 [Bhattacharya 1981].

\begin{tabular}{lcccc}
\hline Layer & $\begin{array}{c}\text { Thickness } \\
(\mathbf{k m})\end{array}$ & $\begin{array}{c}V_{P} \\
(\mathbf{k m} / \mathbf{s})\end{array}$ & $\begin{array}{c}V_{S} \\
(\mathbf{k m} / \mathbf{s})\end{array}$ & $\begin{array}{c}\text { Density } \\
\left(\mathbf{g} / \mathbf{c m}^{3}\right)\end{array}$ \\
\hline 1. Deccan Trap & $0.9 \pm 0.1$ & $4.97 \pm 0.20$ & $2.79 \pm 0.04$ & 2.40 \\
2. Shallow crust & $3.3 \pm 0.3$ & $6.07 \pm 0.07$ & $3.38 \pm 0.05$ & 2.50 \\
3. Upper crust & $14.8 \pm 1.3$ & $6.44 \pm 0.10$ & $3.65 \pm 0.02$ & 2.60 \\
4. Lower crust & $20.6 \pm 1.3$ & $6.83 \pm 0.20$ & $3.87 \pm 0.02$ & 3.01 \\
5. Subcrust & $60.4 \pm 0.2$ & $8.37 \pm 0.08$ & $4.68 \pm 0.01$ & 3.30
\end{tabular}

Table 4. Crustal and Subcrustal Structure for central DVP down to $100 \mathrm{~km}$. Below $100 \mathrm{~km}$ the structure is same as that of IP11 [Bhattacharya 1981]. Thickness of crust $=39.6 \pm 0.2 \mathrm{~km}$. The value after \pm shows corresponding standard deviation. 


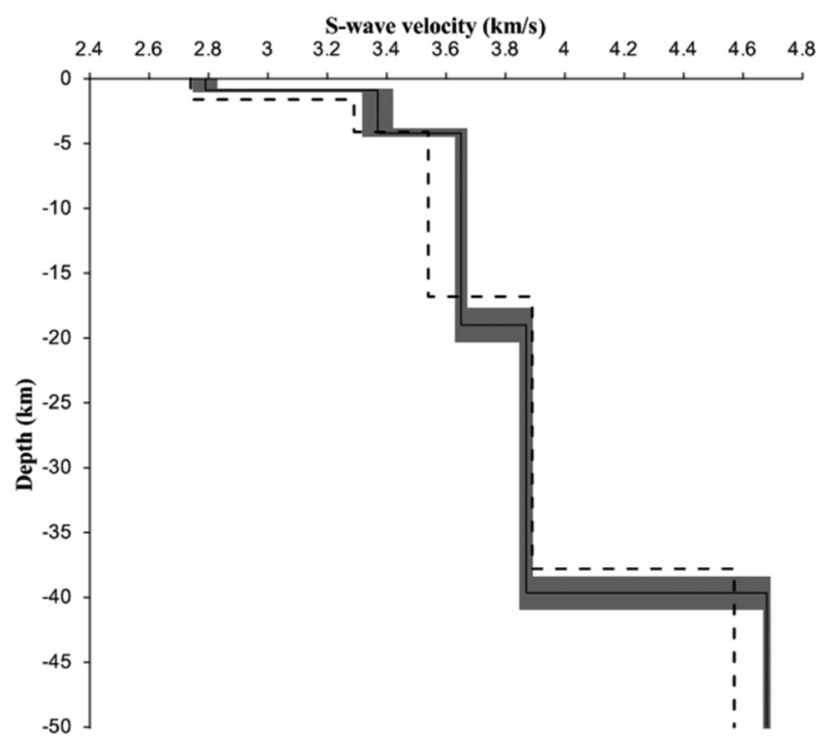

Figure 6. Comparison of velocity structures of central DVP (solid thick line) and northwestern DVP (dashed line). For central DVP (present study), \pm one standard deviation of the velocities and thickness are also shown by shaded areas.

ation in the depth of lower boundary of the upper crust in different study areas of central India and this depth varies between 13.8 and $20.4 \mathrm{~km}$; however, the Moho depth varies only between 38.7 and $40.2 \mathrm{~km}$ and the crustal thickness of $39.6 \mathrm{~km}$ obtained in this study lies in this range.

Figure 6 shows the comparison of velocity structure of central DVP (Table 4) and northwestern DVP (Table 3). The crustal thickness is $39.6 \mathrm{~km}$ at central DVP and it decreases westward becoming $37.8 \mathrm{~km}$ at northwestern DVP. The crustal thickness decreases along with decrease of thicknesses of shallow and upper crust. The thickness of lower crust is nearly constant from central DVP $(20.6 \mathrm{~km})$ to northwestern DVP $(21.0 \mathrm{~km})$ and further westward to the continental shelf $(20.9 \mathrm{~km})$. In the continental shelf, Prajapati et al. [2011] found radial anisotropy in the crust caused by extensional tectonic deformation; it was found that the mean of $S H$ - and $S V$-wave velocities are close to $S$-wave velocity of the isotropic crust of the adjoining northwestern DVP. Such radial anisotropy is not noted either in northwestern DVP or in central DVP. The observation of eastward decrease of trap thickness from 1.6 to $0.9 \mathrm{~km}$ is in agreement with other studies [Harinarayana et al. 2007].

From central DVP in the east to northwestern DVP in the west, $V_{S}$ decreases by 2 to 3 per cent in the shallow and upper crust. Westward decrease of $V_{P}$ is also seen by 3 to 6 per cent in all layers of the crust and subcrust. These differences are above the standard deviations of the evaluated velocities (Table 4) and thus the changes noted are reliable. Heat flow of central DVP is low compared to northwestern DVP [Sen 2001,
Verma 2003]. In the Peninsular India, Sharma et al. [1991] also noted a significant decrease of subcrustal $V_{P}$ in the regions of high heat flow; from this correlation he inferred that low subcrustal $V_{P}$ is associated with elevated temperature of the subcrustal region. Pei et al. [2004] has shown by quantitative analysis of the observed results that subcrustal $V_{P}$ is positively correlated with crustal thickness and negatively correlated with the earth's heat flow. Here we note such correlation with $V_{P}$ not only in the subcrustal regions but also in all layers of the crust (Tables 3 and 4). The past volcanic activity was more on the west than on central part of DVP [Sen 2001]; thus low $V_{P}$ in northwestern DVP also agrees with the past volcanic activity as found by Pei et al. [2004]. In continuation of the study of Sharma et al. [1991], we may infer that the elevated temperature of the crust and subcrust in northwestern DVP is the main factor for causing low velocity in this part of DVP.

\section{Conclusions}

We make the following inferences from the present study across central DVP and previous study across northwestern DVP [Prajapati et al. 2011].

(1) The crustal thickness of central DVP is 39.6 $\mathrm{km}$, which remains in the range between 38.7 and 40.2 $\mathrm{km}$ obtained in other areas of the central India. However, the thickness of upper crust differs significantly at other areas of the central India.

(2) The crustal thickness decreases westward from central DVP $(39.6 \mathrm{~km})$ to northwestern DVP $(37.8 \mathrm{~km})$ along with the decrease of thickness of the upper crust. However, the lower crust has nearly the same thickness.

(3) In a previous study, crustal radial anisotropy was found in the continental shelf adjoining northwestern DVP. Such anisotropy is not noted in the continental part of DVP.

(4) In the shallow and upper crust of DVP, $V_{S}$ decreases by 2 to 3 per cent from east to west, while $V_{P}$ in the whole crust and subcrust decreases by 3 to 6 per cent. The variations of $V_{P}$ and $V_{S}$ are positively correlated with the crustal thickness and negatively correlated with the earth's heat flow. It appears that the elevated crustal subcrustal temperature in the western side is the main factor for low velocities on this side.

Acknowledgements. The first author is thankful to the Director General of Meteorology and Head (Seismology), India Meteorological Department for providing necessary facilities to carry out the study and permission to publish the paper. Comments from anonymous reviewer were useful in improving the manuscript.

\section{References}

Arora, K., V.M. Tiwari, B. Singh, D.C. Mishra and I. Grevemeyer (2012). Three dimensional lithospheric 
structure of the western continental margin of India constrained from gravity modelling: implication for tectonic evolution, Geophys. J. Int., 190, 131150 .

Bhattacharya, S.N. (1981). Observation and inversion of surface wave group velocities across Central India, B. Seismol. Soc. Am., 71, 1489-1501.

Bhattacharya, S.N. (1983). Higher order accuracy in multiple filter technique, B. Seismol. Soc. Am., 73, 1395-1406.

Bhattacharya, S.N. (1987). Reduction of the deep layers in surface wave computation, Geophys. J. R. Astro. Soc., 88, 97-109.

Bhattacharya, S.N. (1991). Surface wave and lithospheric structure across the northwestern part of the Indian Peninsula, Pure Appl. Geophys., 135, 53-59.

Bhattacharya, S.N. (1992). Crustal and upper mantle structure of India from surface wave dispersion, Current Science, 62, 94-100.

Bhattacharya, S.N., and R.S. Dattatrayam (2000). Recent advances in seismic instrumentation and data interpretation in India, Current Science, 79, 13471358.

Dattatrayam, R.S., A.K. Bhatnagar, G. Suresh, P.R. Baidya and J.L. Gautam (2009). Real time earthquake monitoring for early warning of Tsunamis in Indian Ocean region, Mausam, Diamond Jubilee Volume, 253-264.

Dube, R.K., J.C. Bhayana and H.M. Chaudhary (1973). Crustal structure of the Peninsular India, Pure Appl. Geophys., 109, 1718-1727.

Duncan, R.A., and D.G. Pyle (1988). Rapid eruption of the Deccan Traps at the Cretaceous/Tertiary boundary, Nature, 333, 841-843.

Dziewonskei, A., S. Bloch and M. Landisman (1969). A technique for the analysis of transient seismic signals, B. Seismol. Soc. Am., 59, 427-444.

Harinarayana, T., B.P.K. Patro, K. Veeraswamy, C. Manoj, K. Naganjaneyulu, D.N. Murthy and G. Virupakshi (2007). Regional geoelectric structure beneath Deccan Volcanic Province of the Indian subcontinent using magnetotellurics, Tectonophysics, 445, 66-80.

Havskov, J., and L. Ottemoller (1999). SeisAn Earthquake analysis software, Seismol. Res. Lett., 70, 532534.

Lomax, A., and R. Snieder (1995). Finding sets of acceptable solutions with a genetic algorithm with application to surface wave group dispersion in Europe, Gephys. Res. Lett., 21, 2617-2620.

Pei, S.P., Z.H. Xu and S.Y. Wang (2004). Discussion on origin of $P n$ velocity variation in China and adjacent region, Acta Seismologica Sinica, 17, 1-11.
Prajapati, S., G. Suresh and S.N. Bhattacharya (2011). Crustal Structure of the Northwest Deccan Volcanic Province, India, and the Adjoining Continental Shelf from Observed Surface-Wave Dispersion, B. Seismol. Soc. Am., 101, 1488-1495.

Rao, P.N., T. Tsukuda, M. Kosuga, S.C. Bhatia and G. Suresh (2002). Deep lower crustal earthquakes in Central India: inferences from analysis of regional broadband data of the year 1997 May 21, Jabalpur earthquake, Geophys. J. Int., 148, 132-138.

Sen, G. (2001). Generation of Deccan Trap magmas, Proc. Indian Acad. Sci. (Earth Planet. Sci.), 110, 409439.

Sharma, S.R., A. Sundar, V.K. Rao and D.V. Ramana (1991). Surface heat flow and $P n$ velocity distribution in Peninsular India, J. Geodynamics, 13, 67-76.

Singh, S.K., R.S. Dattatrayam, N.M. Shapiro, P. Mandal, J.F. Pacheco and R.K. Midha (1999). Crustal and Upper Mantle Structure of Peninsular India and Source Parameters of the 21 May 1997, Jabalpur Earthquake $(\mathrm{Mw}=5.8)$ : Results from a New Regional Broadband Network, B. Seismol. Soc. Am., 89, 1631-1641.

Suresh, G., S. Jain and S.N. Bhattacharya (2008). Lithosphere of Indus block in the northwest Indian subcontinent through genetic algorithm inversion of surface-wave dispersion, B. Seismol. Soc. Am., 98, 1750-1755.

Verma, S.K. (2003). Geology, geophysics and geodynamics of extensive KCR volcanism during Proterozoic time in India, Long abstracts of 8th Int. Kimberlite Conference, Victoria, Canada, FLA0217.

Yamanaka, H., and H. Ishida (1996). Application of Genetic Algorithms to an Inversion of Surface-Wave Dispersion Data, B. Seismol. Soc. Am., 86, 436-444.

\footnotetext{
${ }^{\star}$ Corresponding author: Gaddale Suresh, India Meteorological Department, Seismology Division, New Delhi, India; email: gsureshimd@yahoo.com.

(C) 2014 by the Istituto Nazionale di Geofisica e Vulcanologia. All rights reserved.
} 